\title{
A Rare Case of Lateral Forefoot Pain: Plantar Adventitious Bursitis
}

\author{
Min Cheol Chang ${ }^{1}$, Wei-Ting Wu ${ }^{2}$, Ke-Vin Chang ${ }^{2}$ \\ 1. Physical Medicine and Rehabilitation, College of Medicine, Yeungnam University, Daegu, KOR 2. Physical Medicine \\ and Rehabilitation, National Taiwan University Hospital Bei-Hu Branch, Taipei, TWN
}

Corresponding author: Ke-Vin Chang, kvchang011@gmail.com

\begin{abstract}
Forefoot pain is a common musculoskeletal complaint but is rarely caused by plantar adventitious bursitis. A 27-year-old female had right lateral forefoot pain for three weeks and was referred for an ultrasound examination, revealing an anechoic mass on top of the flexor digiti minimi brevis tendon. Two weeks after oral medication and a prescription of rocker-bottom shoes, her pain totally disappeared. In conclusion, ultrasound is helpful in differentiating various causes of forefoot pain, which, in this case, facilitated the detection and management of plantar adventitious bursitis.
\end{abstract}

Categories: Physical Medicine \& Rehabilitation, Radiology, Orthopedics

Keywords: pain, forefoot, ultrasonography, plantar adventitious bursitis

\section{Introduction}

The feet transmit the body weight to the ground and maintain the equilibrium of posture during locomotion. During the foot strike, the feet act as a shock absorber and then become the lever for push-off [1]. Since the feet bear the weight of the entire body, the pertinent muscles, tendons, or ligaments are prone to injury. Foot disorders hinder ambulation and worsen patients' quality of life [2]. Tendon sprain, stress fracture, arthritis, interdigital neuroma [3], and intrinsic muscle disorders [4] can elicit foot pain. However, little is known about the pain caused by plantar adventitious bursitis [5]. In this regard, we would like to report a case with lateral forefoot pain caused by plantar adventitious bursitis and how useful ultrasound (US) was for diagnosis.

Received 06/23/2020

Review began 06/28/2020 Review ended 06/28/2020 Published 07/05/2020

\section{() Copyright 2020}

Chang et al. This is an open access article distributed under the terms of the Creative Commons Attribution License CC-BY 4.0., which permits unrestricted use, distribution, and reproduction in any medium, provided the original author and source are credited.

\section{Case Presentation}

A 27-year-old female visited our clinics because of pain in the right lateral and plantar forefoot for three weeks. The pain had an insidious onset and aggravated while walking. She did not participate in any sports. However, due to her job (a waiter), she had to walk and stand for a long period during work hours. Her body weight was 43 kilograms, and no pre-existing musculoskeletal diseases or trauma at her feet was mentioned. During the physical examination, the pain was elicited upon dorsiflexion of the right fifth toe. There was no motor or sensory deficit over the affected area. Tenderness was also observed over the plantar aspect of the right fifth metatarsal bone whereas no local swelling was palpated. The plain radiograph was normal.

She was referred for an ultrasound examination. The linear transducer was placed on the plantar surface in line with the fifth metatarsal bone. When tracing the flexor digiti minimi brevis (FDMB) tendon from its metatarsal origin to the insertion of the fifth proximal phalanx, we identified a non-compressible anechoic mass without increased intralesional vascularity (Figure $1 \mathrm{~A}$ ). In the short-axis view, the lesion was confirmed to be at the bottom of the subcutaneous layer and between the tendons of the FDMB and the abductor digiti minimi muscle (Figure 1B). Sonopalpation over that region reproduced exactly the same pain as the pain she experienced during walking. No similar lesion was identified at the contralateral side (Figures 1C-1D). Plantar adventitious bursitis was diagnosed. Two weeks after oral medication with non-steroid antiinflammatory drugs and a prescription of rocker-bottom shoes, her pain totally subsided. 


\section{Cureus}
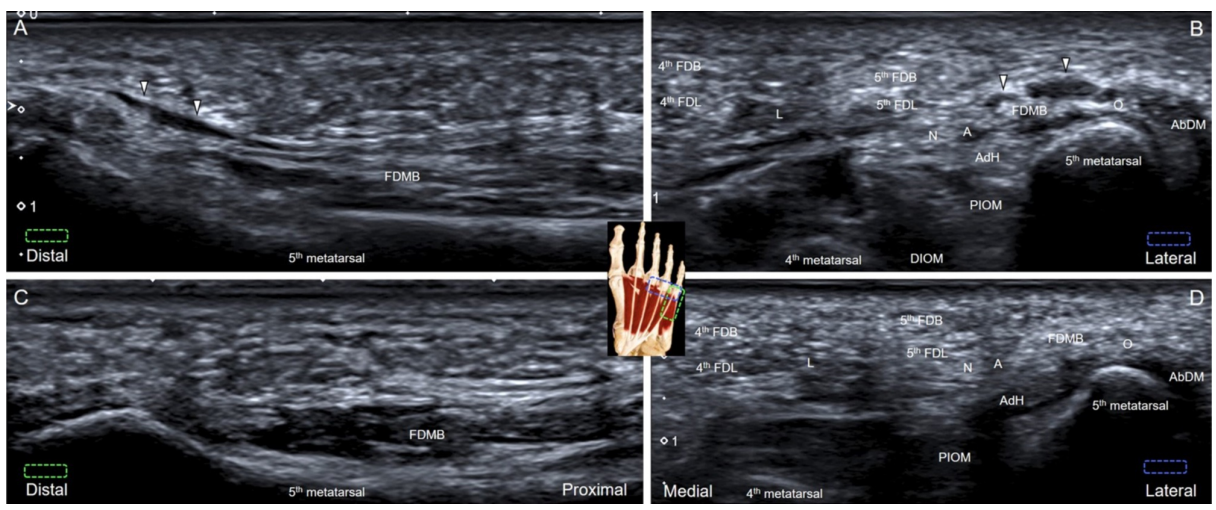

FIGURE 1: Plantar adventitious bursitis

The anechoic mass was noted superficial to the flexor digiti minimi brevis in its long-axis (A) and short-axis view (B). No similar lesion can be identified in the long-axis (C) and short-axis views (D) at the contralateral, asymptomatic side.

White arrowheads: plantar adventitious bursitis

FDB: flexor digitorum brevis; FDL: flexor digitorum longus; AbDM: abductor digiti minimi; PIOM: plantar interosseous muscle; DIOM: dorsal interosseous muscle; N: nerve; A: artery; L: lumbrical muscle; O: opponens digiti minimi; $\mathrm{AdH}$ : transverse head of adductor hallucis

\section{Discussion}

When the feet are loaded on the ground, mechanical energy is stored and then released by the intrinsic muscles, tendons [6], and soft tissues. This function is important for acceleration, deceleration, and change of directions [6], whereas the friction generates shear forces between the plantar adventitious bursa and the aforementioned foot structure [7]. Plantar adventitious bursitis is characterized by myxomatous degeneration and inflammation of superficial fibrous connective tissue [7]. In comparison to the synovial bursa located among muscles, tendons, ligaments, or bones, the inner surface of the adventitious bursa is not lined by synovium [5]. Plantar adventitious bursitis usually occurs at the first and fifth metatarsal heads [4] and should be distinguished from other disorders, including stress fractures, plantar plate ruptures, arthritis, intermetatarsal bursitis, Morton neuromas, and tenosynovitis. All lesions mentioned above are still difficult to diagnose through physical examinations because the related structures are approximated and overlapped together at the plantar area.

US is a useful tool for determining the location and extent of the foot lesions [8-9]. US is widely used in musculoskeletal medicine because it can provide real-time imaging and dynamic assessments $[4,9]$. Scanning the whole metatarsal bones and adjacent joints can help identify stress fractures, plantar plate ruptures [10], and joint arthritis/synovitis. The transducer can be placed along the anterior transverse foot arch for the investigation of Morton neuromas and intermetatarsal bursitis [11].

Tenosynovitis of the flexor digitorum longus (FDL), flexor digitorum brevis (FDB), and FDMB can affect normal ambulation. The investigator can place the transducer parallel to the lateral aspect of the fifth metatarsal bone and track the FDMB to its insertion on the proximal phalanx. Herewith, if the transducer is placed at the medial aspect of the fifth metatarsal bone with its proximal end pointing to the medial foot arc, the FDB and FDL tendons can be clearly visualized along their long axis. The transducer can be redirected to the transverse plane to visualize the hypoechoic fourth lumbrical muscles located beside the FDL tendon.

Some clinical pearls are worth sharing regarding investigation for patients with lateral forefoot pain. First, the investigators should be aware of the fact that the lesions over the forefoot may be difficult to visualize because of the thick keratin layer, which attenuates the US signals [4]. Second, plantar adventitious bursitis occurs at the subcutaneous layer, whereas the underlying toe flexor tendons and intermetatarsal bursa should not be affected.

\section{Conclusions}

The causes of lateral forefoot pain are miscellaneous and difficult to diagnose simply by history taking and physical findings. Static and dynamic US examinations are helpful for differential diagnosis. Since plantar adventitious bursitis is not rare but commonly overlooked, its related foot discomfort is likely to persist if a correct diagnosis is not made. In short, for patients with refractory forefoot pain, we recommend US to be the prioritized imaging tool to investigate its underlying pathology. 


\section{Additional Information \\ Disclosures}

Human subjects: Consent was obtained by all participants in this study. Conflicts of interest: In compliance with the ICMJE uniform disclosure form, all authors declare the following: Payment/services info: Funding information of the article: The current research project was supported by (1) National Taiwan University Hospital, Bei-Hu Branch; (2) Ministry of Science and Technology (MOST 106-2314-B-002-180MY3); (3) Taiwan Society of Ultrasound in Medicine. Financial relationships: All authors have declared that they have no financial relationships at present or within the previous three years with any organizations that might have an interest in the submitted work. Other relationships: All authors have declared that there are no other relationships or activities that could appear to have influenced the submitted work.

\section{Acknowledgements}

Min Cheol Chang and Wei-Ting Wu contributed equally to this manuscript.

\section{References}

1. Malhotra K, Davda K, Singh D: The pathology and management of lesser toe deformities . EFORT Open Rev. 2016, 1:409-419. 10.1302/2058-5241.1.160017

2. Oh-Park M, Kirschner J, Abdelshahed D, Kim DD: Painful foot disorders in the geriatric population. A narrative review. Am J Phys Med Rehabil. 2019, 98:811-819. 10.1097/PHM.0000000000001239

3. Park CH, Chang MC: Forefoot disorders and conservative treatment. Yeungnam Univ J Med. 2019, 36:92-98. 10.12701/yujm.2019.00185

4. Hulstaert T, Shahabpour M, Provyn S, Lenchik L, Simons P, Vanheste R, De Maeseneer M: Forefoot pain in the lesser toes: anatomical considerations and magnetic resonance imaging findings. Can Assoc Radiol J. 2019, 70:408-415. 10.1016/j.carj.2019.06.010

5. Studler U, Mengiardi B, Bode B, Schöttle PB, Pfirrmann CWA, Hodler J, Zanetti M: Fibrosis and adventitious bursae in plantar fat pad of forefoot: MR imaging findings in asymptomatic volunteers and MR imaginghistologic comparison. Radiology. 2008, 246:863-870. 10.1148/radiol.2463070196

6. Kelly LA, Farris DJ, Cresswell AG, Lichtwark GA: Intrinsic foot muscles contribute to elastic energy storage and return in the human foot. J Appl Physiol. 2019, 126:231-238. 10.1152/japplphysiol.00736.2018

7. Foisneau-Lottin A, Martinet N, Henrot P, Paysant J, Blum A, André J-M: Bursitis, adventitious bursa, localized soft-tissue inflammation, and bone marrow edema in tibial stumps: the contribution of magnetic resonance imaging to the diagnosis and management of mechanical stress complications. Arch Phys Med Rehabil. 2003, 84:770-777. 10.1016/s0003-9993(02)04808-6

8. Ansede G, Lee J, Healy J: Musculoskeletal sonography of the normal foot. Skeletal Radiol. 2010, 39:225-242. 10.1007/s00256-009-0697-7

9. Hung C-Y, Chang K-V, Mezian K, Naňka O, Wu W-T, Hsu P-C, Özçakar L: Advanced ankle and foot sonoanatomy: imaging beyond the basics. Diagnostics. 2020, 10:160. 10.3390/diagnostics10030160

10. Ganguly A, Warner J, Aniq H: Central metatarsalgia and walking on pebbles: beyond Morton neuroma . AJR Am J Roentgenol. 2018, 210:821-833. 10.2214/AJR.17.18460

11. Bianchi S: Practical US of the forefoot. J Ultrasound. 2014, 17:151-164. 10.1007/s40477-014-0078-5 